\title{
An alternative to conventional concrete overlay material: Engineered Cementitious Composites (ECC)
}

\author{
H. E. Yücel \& M. Şahmaran \\ Department of Civil Engineering, Gaziantep University, Turkey
}

\begin{abstract}
Rigid pavement overlays have been used for construction and repair applications of structures such as highways, bridge-decks and airports for many years. Although, rigid pavement overlays have advantages as long service life and high durability, problems are encountered particularly on reflective cracking and bond properties. The superior ductility with high strength and improved durability characteristics suggest that the Engineered Cementitious Composites (ECC) could be used as an attractive alternative to conventional concrete overlay materials. In this paper, emphasis is placed on the accumulated knowledge on rigid pavement overlay performances of high volume fly ash or ground granulated blast furnace slag incorporated ECC under typical mechanical loads associated with traffic and environment. Fatigue performance, flexural behavior, reflective cracking characteristics and bond properties (by slant shear test) between the overlay and substrate concrete were investigated as performance criteria. As a result, ECC has important potential to be used as an overlay material.

Keywords: Engineered Cementitious Composites (ECC), rigid pavement overlay, fatigue performance, reflective cracking, bond strength.
\end{abstract}

\section{Introduction}

Pavement is the durable surface coating material laid down on a specific area desired to sustain traffic. The basic role of the pavement construction is to 
disperse wheel loads over a large area of the ground. In general, there are two types of pavements as rigid and flexible (asphalt), according to dissipation of surface loads. While rigid concrete pavements disperse the wheel loads quite homogeneously over the area of the pavement, asphalt concrete pavements distribute the load over a cone-shaped area under the wheel [1]. Although, asphalt concrete pavements are used for all applications of transportation structures, the use of rigid concrete pavements has become increasingly popular for places subjected to moderate and heavy traffic loads, such as bridge decks, highways (especially intersections), airport pavements and industrial floor rehabilitation applications, due to their high load carrying capacity and low maintenance requirement compared to asphalt concrete pavements [2]. Hundred thousand kilometers of rigid concrete pavements had been built all over the world in the past decades. At present, most of those concrete pavements are either approaching the end of their design lives or in need of repair [3]. For pavements subjected to moderate and/or heavy traffic, the most common rehabilitation method is to place an overlay on the existing pavement. These systems have been used around the world for the protection of pavements, but the premature delaminations and failures have been observed in many cases [4]. Especially, reflective cracking and bond strength problems have occurred after the pavement rehabilitation procedure. Therefore, a new generation material is needed to prevent these failure problems.

During the last decade concrete technology has been undergoing rapid development. The effort to modify the brittle behavior of plain cementitious materials such as mortars and concretes has resulted in modern concepts of high performance fiber reinforced cementitious composites (HPFRCC). Engineered Cementitious Composites (ECC) is a newly developed HPFRCC with substantial benefit in high ductility and improved durability characteristics. Because of these advanced properties, ECC could be used as an attractive alternative to conventional concrete overlay materials $[5,6]$. Also, the application of ECC in the repair layer over an existing concrete substrate supports this idea [2, 6, 7].

The performance of a pavement overlay material is dependent on the behavior under fatigue loading, load carrying and deformation capacities under flexural loading, reflective cracking characteristics and bond properties with the substrate. Therefore, the present study is focused on the accumulated knowledge of these performance parameters of high volume fly ash or ground granulated blast furnace slag incorporated ECC.

\section{Engineered Cementitious Composites (ECC)}

The most distinctive characteristic separating ECC from conventional concrete and fiber reinforced concrete (FRC) is an ultimate tensile strain capacity between 3 to $5 \%$, depending on the specific ECC mixture. This strain capacity is realized through the formation of many closely spaced microcracks, allowing for a strain capacity over 300 times that of normal concrete. These cracks, which carry increasing load after formation, allow the material to exhibit strain hardening, similar to many ductile metals. 
While the components of ECC may be similar to FRC, the distinctive ECC characteristic of strain hardening through microcracking is achieved through micromechanical tailoring of the components (i.e. cement, sand, and fibers) along with control of the interfacial properties between components (fiber, matrix and fiber-matrix interface) [8-10]. Fracture properties of the cementitious matrix are carefully controlled through mix proportions. Fiber properties, such as strength, modulus of elasticity, and aspect ratio have been customized for use in ECC. The interfacial properties between fiber and matrix have also been optimized in cooperation with the manufacturer for use in this material. Typical mix proportions of ECC using a poly-vinyl-alcohol (PVA) fiber are given in Table 1.

Table 1: $\quad$ Typical mixture design of ECC material.

\begin{tabular}{|c|c|c|c|c|c|}
\hline Cement & Water & Sand & Mineral admixture & HRWR $^{* *}$ & Fiber (\%) \\
\hline 1.00 & 0.58 & 0.80 & 1.20 & 0.013 & 2.00 \\
\hline
\end{tabular}
${ }^{*}$ Mineral admixture (Fly ash or ground granulated blast furnace slag)
HRWR = High range water reducer; all ingredient proportions by
weight except for fiber.

While most HPFRCCs rely on a high fiber volume to achieve high performance, ECC uses relatively low amounts, typically $2 \%$ by volume, of short, discontinuous fiber. This low fiber volume, along with the common components, allows flexibility in construction execution. To date, ECC materials have been engineered for self-consolidation casting [11], extrusion [12], shotcreting [13], and conventional mixing in a gravity mixer or conventional mixing truck [14].

Figure 1 shows a typical uniaxial tensile stress-strain curve of ECC material containing 2\% poly-vinyl-alcohol (PVA) fiber [15]. The characteristic strainhardening behavior after first cracking is accompanied by multiple microcracking. The crack width development during inelastic straining is also shown in Figure 1. Even at ultimate load, the crack width remains smaller than $100 \mu \mathrm{m}$. This tight crack width is self-controlled and, whether the composite is used in combination with conventional reinforcement or not, it is a material characteristic independent of rebar reinforcement ratio. Under severe bending load, an ECC beam deforms similarly to a ductile metal plate through plastic deformation with the development of multiple cracks with small crack spacing and tight crack widths $(<0.1 \mathrm{~mm})$. Microcracks developed from the first cracking point and spread out in the mid-span of the flexural beam. Bending failure in ECC occurred when the fiber bridging strength at one of the microcracks was reached resulting in localized deformation at this section once the modulus of rupture is approached. In compression, ECC materials exhibit compressive strengths similar to high strength concrete (e.g. greater than $60 \mathrm{MPa}$ ) [14]. 


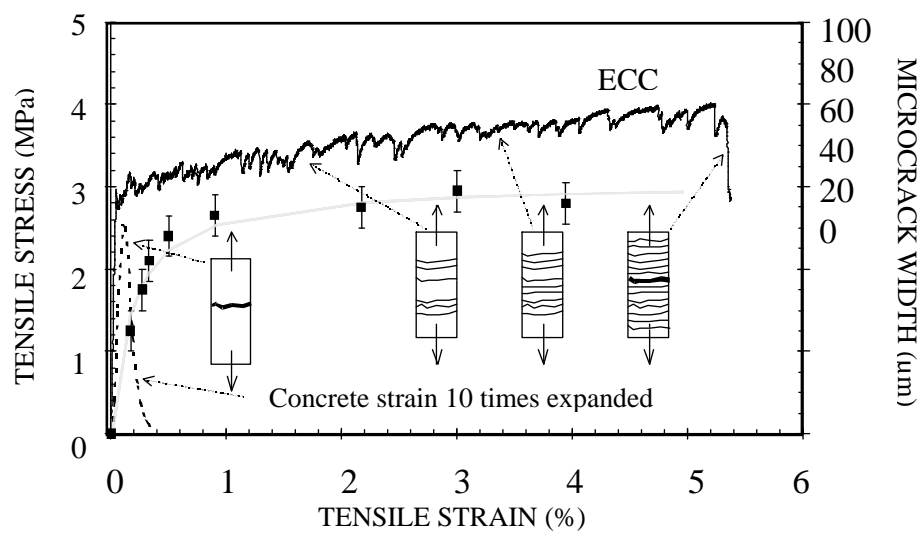

Figure 1: Typical tensile stress-strain curve and crack width development of ECC.

\section{Performance of ECC as pavement overlay material}

\subsection{Fatigue performance}

Fatigue is the process of cumulative damage of structure resulting from repeated loading. At least half of all mechanical failures are due to fatigue in the structures all over the world. It is more important for pavement applications because of the repeated traffic loads. The performance of ECC has been investigated in high fatigue scenarios, such as rigid pavement overlay rehabilitation.

Zhang and $\mathrm{Li}$ [2] studied the fatigue performance of ECC as pavement overlay. In this overlay application, reflective cracking through the new overlay is of greatest concern. Existing cracks and locally reduced load capacity in the substrate pavement can result in flexural fatigue within the overlay structure. As control mixture, conventional plain concrete (PC) was designed for rigid pavement overlay material. Also, ECC was produced as pavement overlay material without any mineral admixture. To evaluate ECC performance, both ECC/concrete and PC/concrete overlay specimens were tested in flexural fatigue. Test results show that the load carrying capacity of ECC/concrete overlay specimens was double that of PC/concrete overlay specimens, the deformability of ECC/concrete specimens was significantly higher, and the fatigue life was extended by several orders of magnitude. Similar advantages in the fatigue resistance of ECC have also been found in comparison to polymer cement mortars [16] and PC [17].

Fatigue resistance of ECC for repair of viaducts subjected to train loading was studied by Inaguma et al. [18]. This study showed that in the case of spraying a $10 \mathrm{~mm}$ thickness of ECC, delamination or spalling of the cover were not observed under the fatigue application that is equivalent to 20 years exposure to 
the loadings of passing trains. Therefore, in fatigue-prone concrete infrastructure, the application of ECC materials could significantly lengthen service-life, reduce maintenance events, and life cycle costs.

\subsection{Flexural behavior}

To determine flexural behavior of ECC material, a detailed study was conducted by Yucel et al. [19]. In this study, two different ECC mixtures, with fly ash (F_ECC) and ground granulated blast furnace slag (S_ECC) were used as rigid pavement overlay material. Micro-silica concrete (MSC), that is used as pavement overlay material in general, was selected as control mixture. To determine the flexural performance of layered overlay/concrete composite beams, four point bending tests were carried out with MSC, F_ECC and S_ECC overlay surfaces on the bottom (in tension) and concrete surface on the top (in compression) as in the field condition. Three different overlay thicknesses as 25 $\mathrm{mm}, 35 \mathrm{~mm}$ and $50 \mathrm{~mm}$, were used to evaluate the effect of overlay thickness on flexural performance. Maximum flexural stress of F_ECC, S_ECC and MSC composite beams after four point bending test are summarized in Table 2. Test results showed that ECC overlaid specimens were superior to MSC overlaid specimens in terms of flexural strength regardless of the thickness of overlay. Among the ECC specimens, S_ECC composite beam has the highest flexural strength for each pavement overlay thickness and testing age. Based on the results, it can be concluded that the addition of ECC layer could significantly improve the maximum flexural stress. Moreover, when the thickness of pavement overlay increases, the percentage of improvement with the use of ECC increased. It is important to note that, the maximum flexural load carrying capacities of $35 \mathrm{~mm}$ thickness ECC composite beams have a higher maximum flexural load carrying capacity than MSC composite beam with the thickness of $50 \mathrm{~mm}$. The crack propagations of MSC, S_ECC and F_ECC composite beams after four point bending test can be seen in Figure 2. For MSC composite beam, there is only one major crack propagating from the bottom of the beam (Figure 2(c)). For S_ECC and F_ECC composite beams, multiple fine cracks are formed in the ECC layer first (Figure 2(a) and (b)). Finally, one of these cracks will open more widely than the others and propagate into the concrete layer. Multiple cracking permits large straining in the ECC layer until its failure, therefore leading to a higher ultimate deflection value and a ductile failure mode. It is also important to note that both ECC overlay systems failed without delamination for all studied thicknesses in these experiments (Figure 2(a) and (b)). However, regardless of the thickness of overlay, slight delamination between the substrate concrete and MSC overlay materials was observed (Figure 2(c)).

Flexural behavior of ECC material was also studied by Zhang and Li [2], Lim and $\mathrm{Li}$ [6], and Kamada and $\mathrm{Li}$ [7]. In these researches ECC was compared with PC and steel fiber reinforced concrete (SFRC) as rigid pavement overlay. Similar results with the study of Yucel et al. [19] were obtained from the works. All of these studies show that ECC has superior flexural performance without delamination than PC and SFRC. 
Table 2: $\quad$ Flexural strengths of F-ECC, S-ECC and MSC composite beams after four point bending test.

\begin{tabular}{|c|c|c|c|c|}
\hline \multirow{2}{*}{ Mix ID } & \multirow{2}{*}{$\begin{array}{c}\text { Thickness } \\
\text { (mm) }\end{array}$} & \multicolumn{3}{|c|}{ Flexural Strength, MPa } \\
\hline & & 1 day & 7 days & 28 days \\
\hline F_ECC & \multirow{3}{*}{25} & 4.83 & 7.55 & 9.46 \\
\hline S_ECC & & 6.30 & 8.94 & 10.88 \\
\hline MSC & & 4.64 & 5.33 & 6.07 \\
\hline F_ECC & \multirow{3}{*}{35} & 5.12 & 8.12 & 9.98 \\
\hline S_ECC & & 6.31 & 9.90 & 11.00 \\
\hline MSC & & 4.80 & 5.59 & 6.22 \\
\hline F_ECC & \multirow{3}{*}{50} & 5.29 & 8.50 & 11.31 \\
\hline S_ECC & & 6.58 & 10.48 & 11.98 \\
\hline MSC & & 4.85 & 6.11 & 6.51 \\
\hline
\end{tabular}

\subsection{Reflective cracking performance}

Reflective cracking occurs when the existing cracks in the underlying pavements reflect into the newly constructed overlay under shrinkage and/or temperature change, and traffic loads. Cracking in overlay slabs reduces the load carrying capacity, allows water and other aggressive agents, such as deicing salts, to go through the cover layer to come into contact with the reinforcement bars, leading to corrosion and rupture. In addition to the reflective cracking, due to the change in deformation behavior between new constructed overlay and old pavement under mechanical and environmental loading, a certain delamination along the interface of overlay and old pavement starting from the existing cracks will take place [2]. Therefore, the prevention of overlay delamination and reflective cracking in overlaid slabs are crucial.

Reflective cracking performance of ECC was researched by Zhang and Li [2], Lim and Li [6], Kamada and Li [7], and Yucel et al. [19]. In all of these studies, a similar composite beam is utilized with four-point bending load applied to the beam as a loading condition, to simulate the reflective cracking in overlaid pavements. Details of the test set-up can be seen in Figure 3.

In the study of Zhang and Li [2] PC and ECC mixtures; in the study of Lim and $\mathrm{Li}$ [6], and Kamada and Li [7] PC, SFRC and ECC mixtures were selected as rigid pavement overlay material. Four point bending test was performed for all types of overlay mixtures to determine reflective cracking performances. According to the test results, in the ECC overlay system, the ultimate load is about 2 to 2.5 times larger than that of the PC overlay system and 1 to 1.25 larger than that of the SFRC overlay system. Also it is similar for deflection at peak load, a reflection of the system ductility and energy absorption capacity. In the ECC overlay system, several kinking and trapping behaviors are observed. The microcracking deformation mechanism of ECC effectively eliminated reflective cracking. 


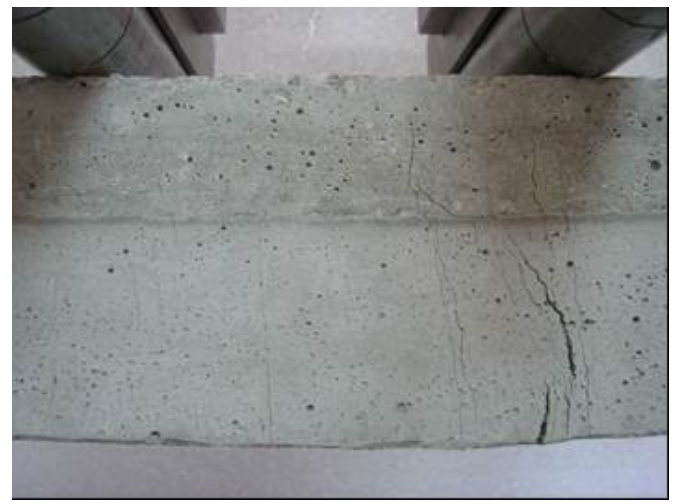

(a)

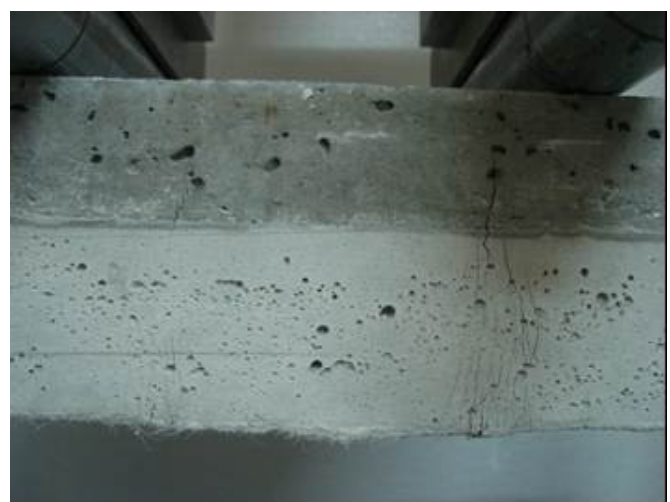

(b)

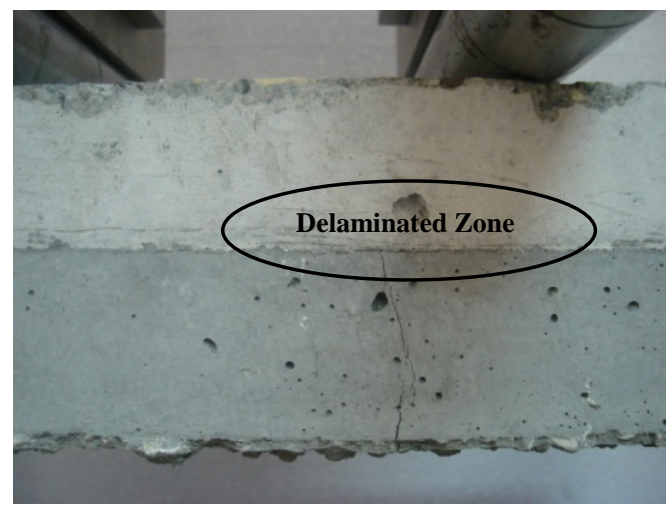

(c)

Figure 2: Crack propagations of layered composite beams after four point bending test (a) F_ECC, (b) S_ECC and (c) MSC. 


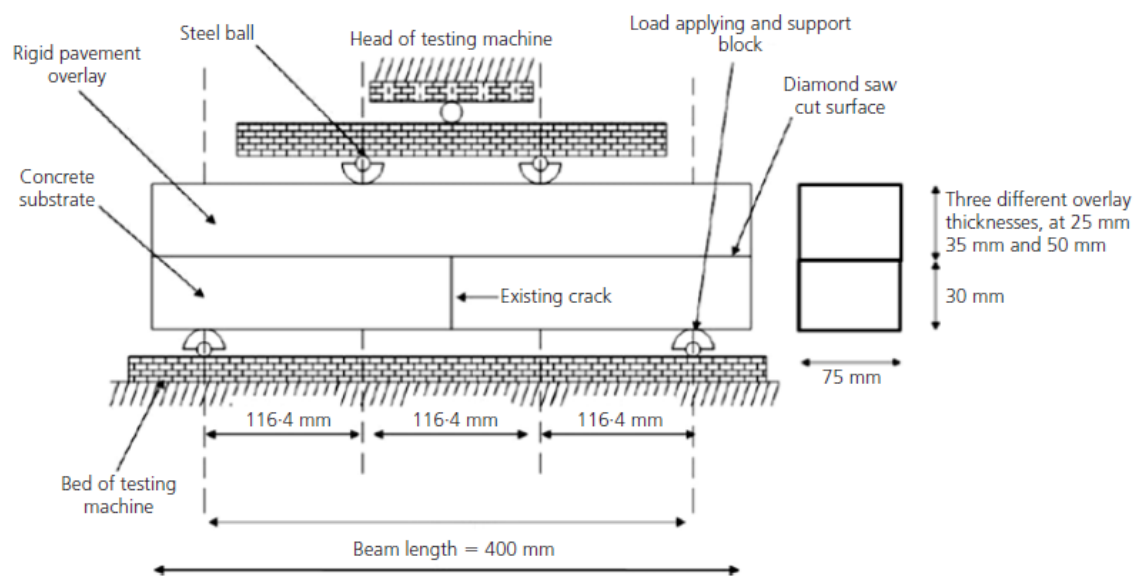

Figure 3: $\quad$ Model of four-point bending for reflective cracking test.

In the study of Yucel et al. [19] F_ECC, S_ECC and MSC mixtures were tested to determine and compare reflective cracking performances. In this research, similar results with the studies explained before were observed. The most significant differences in external appearance after testing between the ECC overlay systems and the MSC overlay system are the number of cracks and the crack width. In the MSC composite beams, only one crack at the initial notch in the overlay systems is found and this crack opening is the final failure of the MSC overlay system (Figure 4(a)). However in the ECC overlay systems with smooth surface, for both ECC mixtures, multiple microcracks are developed on both sides of the initial notch increasing with the deflection of specimens (Figure 4(b) and (c)). This means that the ECC overlay system was able to redistribute the load and utilize more material to resist the final failure. Multiple cracking also enables large deformation under flexural loading in the ECC layer before its failure, therefore leading to a higher ultimate deflection value and a ductile failure mode without direct crack reflection. In addition, different overlay thicknesses as $25 \mathrm{~mm}, 35 \mathrm{~mm}$ and $50 \mathrm{~mm}$, were applied to determine the thickness effect of overlay mixtures. When the overlay thicknesses are compared, S_ECC mixture with the thickness of $35 \mathrm{~mm}$ can be used instead of $50 \mathrm{~mm}$ thick MSC mixture in accordance with maximum flexural loads resulted in reflective cracking test.

\subsection{Bond properties}

The most critical problem with failure of pavement overlay materials is delamination due to bond failure at the interface [20]. Therefore, one of the most important parameter for pavement overlay materials is bond properties. To determine bond properties of ECC, a study was performed by Sahmaran et al. [21]. In this research, slant shear test was selected to evaluate bond strength of 


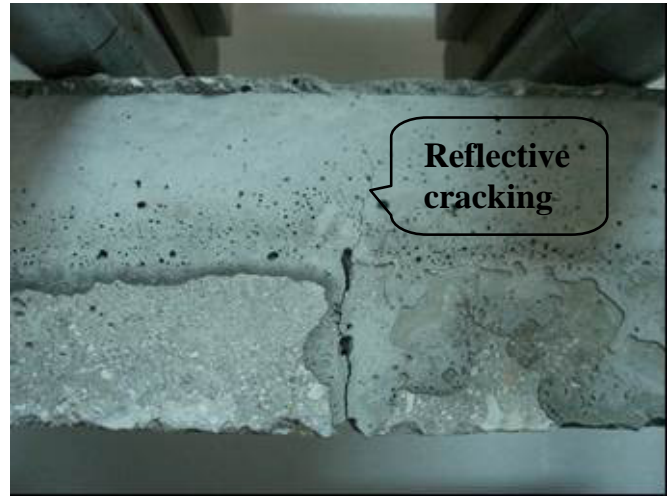

(a)

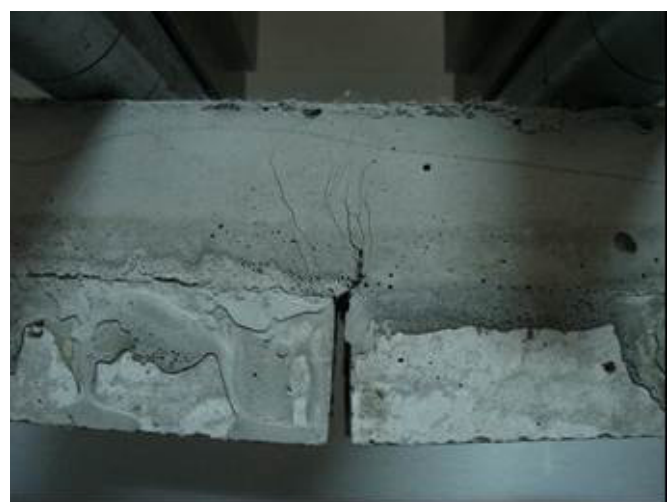

(b)

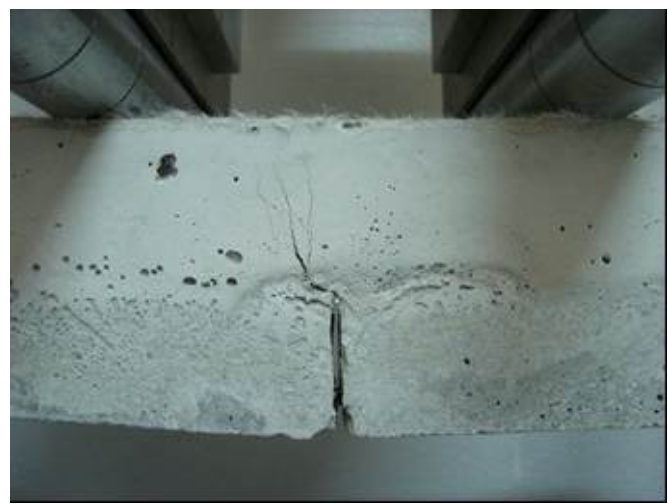

(c)

Figure 4: Crack patterns at failure of overlay materials after reflective cracking test (a) MSC, (b) F_ECC and (c) S_ECC. 
overlay mixtures. The slant shear test, which measures bond strength under combined shear and compression stresses has become one of the most widely accepted methods for evaluating the bond of repair materials to concrete substrates. In this test, the repair material is bonded to a substrate concrete specimen on a slant elliptical plane inclined at an angle of $30^{\circ}$ from the loading axis to form a $100 \times 200 \mathrm{~mm}$ composite cylinder. F_ECC, S_ECC and MSC mixtures were prepared as overlay material for slant shear test. Table 3 shows the results of slant shear tests of F_ECC, S_ECC, and MSC bi-layer composite cylinder specimens including the modes of failure. The test results show that ECC specimens resulted bond strength that are approximately $15-20 \%$, higher than the MSC specimens. It can be concluded that the addition of ECC layer could significantly improve the bond stress measured by slant shear test. Three different failure modes were observed as substrate, slanted interface and monolithic rupture in this slant shear test. The failure type for MSC/concrete specimens was interface debonding or monolithic rupture. In all cases of ECCsubstrate bi-layer specimens, the failure plane occurred preferentially through the substrate, for both types of ECC mixtures. This is due to the effectiveness of the ECC with its high adhesion strength that did not allow the interface to fail. Failure through the substrate concrete is always desirable, because failure through the substrate concrete demonstrated that the existing substrate is the weakest component of the ECC/concrete system. Consequently, the bond strength increased greatly.

Table 3: $\quad$ Slant shear bond strength test results and failure mode.

\begin{tabular}{|l|c|c|c|l|}
\hline \multirow{2}{*}{ Mix. ID } & \multicolumn{3}{|c|}{ Bond Strength (MPa) } & \multicolumn{1}{c|}{ Failure Mode } \\
\cline { 2 - 5 } & 1 Day & 7 Days & 28 Days & \multicolumn{1}{c|}{ Days } \\
\hline F_ECC & 7.1 & 14.7 & 21.7 & All through substrate \\
\hline S_ECC & 8.3 & 17.4 & 24.3 & All through substrate \\
\hline MSC & 10.4 & 14.1 & 15.6 & $\begin{array}{l}\text { 4 through slanted interface } \\
\text { 2 through a monolithic rupture }\end{array}$ \\
\hline
\end{tabular}

\section{Conclusions}

The results found in the studies summarized in this paper largely confirm the rigid pavement overlay performance of ECC material. The results can be summarized as follows:

- According to the test results under flexural fatigue loading, the load carrying capacity of ECC/concrete overlay specimens was double that of PC/concrete overlay specimens, the deformability of ECC/concrete specimens was significantly higher, and the fatigue life was extended.

- For the same geometry and flexural loading conditions, layered ECC beams have significantly increased both load-carrying capacity and deformability, and show better crack width control in comparison with PC, MSC and SFRC composite beams.

- As the overlay material, ECC is found to be effective in eliminating the reflective cracking and delamination failure in repaired and overlay systems. 
- ECC overlay with $35 \mathrm{~mm}$ thick is superior to MSC overlay with $50 \mathrm{~mm}$ thick for rehabilitating concrete pavements.

- Based on the slant shear test results, it can be concluded that ECC can achieve adequate bond strength with other concretes. All ECC-substrate bilayer specimens had failure plane occur preferentially through the substrate, for both types of mixtures. On the other hand, for MSC-substrate specimens, the failure type was interface debonding or monolithic rupture.

Specifically, the environmental or mechanical loading condition and geometry of repair can be much more complex than the idealized tests conducted in these investigations. Therefore, further work is in progress to examine the performance of pavements with thin overlays under these conditions.

\section{References}

[1] Atkinson, Harold N. Highway materials, soils and concretes (4 ${ }^{\text {th }}$ ed.). Prentice Hall: USA, pp. 162, 2003.

[2] Zhang, J. and Li, V.C. Monotonic and fatigue performance in bending of fiber reinforced engineered cementitious composite in overlay system. Journal of Cement and Concrete Research, 32 (3), pp. 415-423, 2002.

[3] Emmanuel, B.O.A., Lev K. and Leslie, T. G. Mechanistic-based model for predicting reflective cracking in asphalt concrete-overlaid pavements. Transportation Research Record, 1629, pp. 234-241, 1998.

[4] Davalos, J.F., Ray, I., Sun, Z. and Hong, T. Interface Bond Characterization of High-Performance Concrete Overlays and Substrate. ACI Special Publication, 228, pp. 917-932, 2005.

[5] Lepech, M. D., and Li, V. C. Sustainable pavement overlays using engineered cementitious composites. International Journal of Pavement Research and Technology, 3(5), pp. 241-250, 2010.

[6] Lim Y. M. and Li V. C. Durable repair of aged infrastructures using trapping mechanism of engineered cementitious composites. Cement and Concrete Composites, 19(4), pp. 373-385, 1997.

[7] Kamada, T. and Li, V.C. The effects of surface preparation on the fracture behavior of ECC/concrete repair system. Journal of Cement and Concrete Composites, 22(6), pp. 423-431, 2000.

[8] Li, V.C. ECC - Tailored Composites through Micromechanical Modeling. Fiber Reinforced Concrete: Present and the Future, edited by Banthia et al., CSCE, Montreal, pp. 64-97, 1998.

[9] Li, V.C. On engineered cementitious composites (ECC) - a review of the material and its applications. Journal of Advanced Concrete Technology, 1 (3), pp. 215-230, 2003.

[10] Li, V.C., Wang, S. and Wu. C. Tensile Strain-Hardening Behavior of PVAECC. ACI Materials Journal, 98 (6), pp. 483-492, 2001.

[11] Kong, H. J., Bike, S. and Li, V.C. Development of a Self-Compacting ECC Employing Electrosteric Dispersion/Stabilization. Cement and Concrete Composites, 25 (3), pp. 301-309, 2003. 
[12] Stang, H., and Li, V.C. Extrusion of ECC-Material. Proceeding of High Performance Fiber Reinforced Cement Composites 3 (HPFRCC 3), edited by H. Reinhardt and A. Naaman, Chapman \& Hull, pp. 203-212, 1999.

[13] Kim, Y.Y., Kong, H. J., and Li, V.C. Design of Engineered Cementitious Composite (ECC) Suitable for Wet-Mix Shotcreting. ACI Materials Journal, 100 (6), pp. 511-518, 2003.

[14] Lepech M. and Li, V. C. Large Scale Processing of Engineered Cementitious Composites. ACI Materials Journal, 105 (4), pp. 358-366, 2008.

[15] Weimann, M. B., and Li, V.C. Hygral Behavior of Engineered Cementitious Composites (ECC). International Journal for Restoration of Buildings and Monuments, 9 (5), pp. 513-534, 2003.

[16] Suthiwarapirak, P., Matsumoto, T. and Kanda, T. Flexural fatigue failure characteristics of an Engineered Cementitious Composite and Polymer Cement Mortars. Materials, Conc. Struc. Pavements, 57, pp. 121-134, 2002.

[17] Qian, S. and Li, V.C. Durable pavement with ECC. Proc. of the $1^{\text {st }}$ International Conference on Microstructure Related Durability of Cementitious Composites, Nanjing, China, pp. 535-543, 2008.

[18] Inaguma, H., Seki, M., Suka, K. and Rokugo, K. Experimental study on crack-bridging ability of ECC for repair under train loading. Proc. of Int'l Workshop on HPFRCC in Structural Applications, Honolulu, Hawaii, USA., pp. 499-508, 2005.

[19] Yucel, H. E., Sahmaran, M., Jashami, H., Guler, M. and Yaman, I.O. Thin ECC Overlay Systems for Rehabilitation of Rigid Concrete Pavements. Magazine of Concrete Research, 65 (2), pp. 108-120, 2013.

[20] Davalos, J. F., Ray, I., Sun, Z. and Hong, T. Interface bond characterization of high-performance concrete overlays and substrate. ACI Special Publication, 228, pp. 917-932, 2005.

[21] Sahmaran, M., Yucel, H. E., Yildirim, G., Al-Emam, M. and Lachemi, M. Investigation of bond between concrete substrate and ECC overlays. ASCE Journal of Materials in Civil Engineering, (In press), 2013. 